\title{
Empathische Ethnomedizin
}

\section{Iris Ritzmann}

Prof. Dr. med. et lic. phil., Mitglied der Redaktion Medizingeschichte

Die Künstlerin und Naturwissenschaftlerin Maria Sibylla Merian (1647-1717) ist vor allem über ihre farbintensiven, lebensnahen Bilder von Raupen und Schmetterlingen in die Geschichte eingegangen. Weniger bekannt ist, dass diese Bilder einen neuen Typus der naturkundlichen Darstellung verkörperten, die Gruppierung verschiedener Entwicklungsstadien eines Insekts rund um die zugehörige Futterpflanze. Erst in den letzten Jahrzehnten wurden schliesslich ihre ethnomedizini-

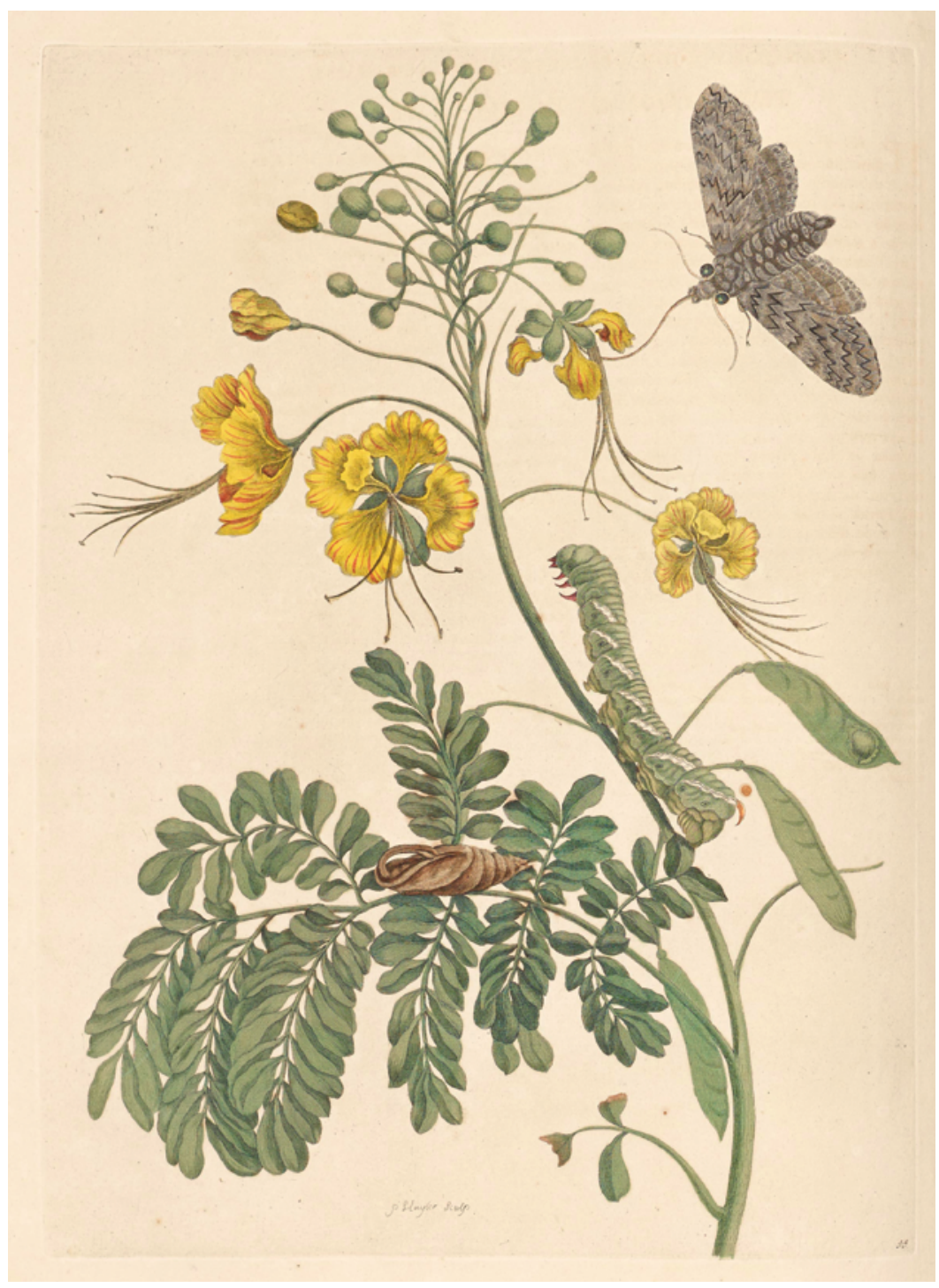

Flos Pavonis, handkolorierter Kupferstich auf Tafel 45, in Maria Sibylla Merian:

Dissertatio de Generatione. Surinam, gold- und silberkolorierte Ausgabe, Den Haag 1726, Sammlung Dr. Franz Käppeli. schen Beiträge wahrgenommen. Dabei stehen diese verschriftlichten Beobachtungen an mehreren Stellen im berühmtesten ihrer Werke, der Metamorphosis insectorum Surinamensium.

Das Buch zu ihrer abenteuerlichen Surinam-Expedition stellte die über 50-jährige Künstlerin und Wissenschaftlerin in den Jahren nach ihrer Rückkehr nach Amsterdam fertig. Ganz allein hatte Merian die Reise in die südamerikanische Sklavenkolonie nicht unternommen: Sie wurde von ihrer jüngsten Tochter begleitet. Zwei Jahre hielten die beiden Frauen durch. In dieser Zeit beschrieb Merian Schmetterlinge und Raupen, Echsen und Schlangen, Bäume und Blumen - aber auch Menschen, die aus den Pflanzen Heilmittel herstellten und der Europäerin von ihren Lebensgewohnheiten erzählten.

Zur Flos Pavonis, der Pfauenblume, schreibt sie: «Flos pavonis ist eine neun Fuss hohe Pflanze mit gelben und roten Blüten. Ihr Samen wird von Frauen gebraucht, die Geburtswehen haben und weiterarbeiten sollen. Die Indianer, die bei Holländern im Dienst stehen und nicht gut behandelt werden, treiben damit ab, damit ihre Kinder nicht auch Sklaven werden müssen. Die schwarzen Sklavinnen aus Guinea und Angola müssen sehr zuvorkommend behandelt werden, denn sonst wollen sie als Sklavinnen keine Kinder gebären. Sie bekommen auch keine, ja sie nehmen sich zuweilen sogar das Leben wegen der üblichen harten Behandlung, die man ihnen zuteil werden lässt. Sie meinen, dass sie in ihrem Land als Freie wiedergeboren werden, so wie sie mir aus eigenem Munde berichtet haben.»

Erst nach dieser Schilderung folgt ein kurzer Absatz über die Raupen, die Merian auf der Pflanze gesammelt hatte und aus denen schliesslich graue Falter schlüpften. Lebensecht bringt sie die Motte zu Papier, die mit ihrem Rüssel Nektar aus der goldgelben Blüte saugt. Nur diese naturkundliche Beschreibung wurde von ihren Zeitgenossen wahrgenommen, nicht aber ihr kritisches Zeugnis über die unmenschlichen $\mathrm{Zu}$ stände in der Sklavenkolonie.

Vor genau dreihundert Jahren starb Maria Sibylla Merian - völlig verarmt. Ihr Lebenswerk aber gibt bis heute zu Reden.

Bildnachweis

๑) Museum für medizinhistorische Bücher Muri (mmbm.ch) 